\title{
Glassy steel optimized for glass-forming ability and toughness
}

\author{
Marios D. Demetriou, ${ }^{\text {a) }}$ Georg Kaltenboeck, Jin-Yoo Suh, Glenn Garrett, Michael Floyd, \\ Chase Crewdson, Douglas C. Hofmann, Henry Kozachkov, Aaron Wiest, \\ Joseph P. Schramm, and William L. Johnson \\ Keck Engineering Laboratories, California Institute of Technology, Pasadena, California 91125, USA
}

(Received 4 June 2009; accepted 1 July 2009; published online 31 July 2009)

\begin{abstract}
An alloy development strategy coupled with toughness assessments and ultrasonic measurements is implemented to design a series of iron-based glass-forming alloys that demonstrate improved glass-forming ability and toughness. The combination of good glass-forming ability and high toughness demonstrated by the present alloys is uncommon in Fe-based systems, and is attributed to the ability of these compositions to form stable glass configurations associated with low activation barriers for shear flow, which tend to promote plastic flow and give rise to a toughness higher than other known Fe-based bulk-glass-forming systems. (c) 2009 American Institute of Physics. [DOI: 10.1063/1.3184792]
\end{abstract}

The remarkably high strength, modulus, and hardness of iron-based glasses, combined with their low cost, prompted an effort over the past five years to design amorphous steel suitable for structural applications. The development effort yielded glasses with critical rod diameters as large as $12 \mathrm{~mm}$ 1,2 and strengths in excess of $4 \mathrm{GPa}^{3}{ }^{3}$ These low-cost ultrastrong materials however exhibit fracture toughness values as low as $3 \mathrm{MPa} \mathrm{m}{ }^{1 / 2}{ }^{4}$ well below acceptable toughness limits for structural materials. The low toughness has been linked to their elastic constants, specifically their high shear modulus, ${ }^{5}$ which for some compositions exceeds $80 \mathrm{GPa}^{3}$ Recent efforts to toughen these alloys by altering their composition yielded glasses with lower shear moduli (below 70 $\mathrm{GPa}$ ), which exhibit improved notch toughness (as high as $50 \mathrm{MPa} \mathrm{m}^{1 / 2}$ ) but compromised glass-forming ability (critical rod diameters less than $3 \mathrm{~mm}$ ). ${ }^{5,6}$ In this study, we implement an alloy development strategy coupled with toughness assessment and ultrasonic measurements to design glassy steel alloys with particularly low shear moduli (below 60 $\mathrm{GPa}$ ) that demonstrate high toughness (notch toughness in excess of $50 \mathrm{MPa} \mathrm{m}{ }^{1 / 2}$ ) yet adequate glass-forming ability (critical rod diameters as large as $6 \mathrm{~mm}$ ).

The link between the high shear modulus and the low toughness of Fe-based glasses rests on the argument that a high shear modulus implies a high resistance to relax stress by shear flow. In turn, this promotes cavitation and early fracture and thus limits toughness. Using a Frenkel-like analysis to study cooperative shearing, Johnson and Samwer ${ }^{7}$ arrived at a quantitative expression for the activation energy for shear flow, that is, the energy barrier to initiate plastic flow. Specifically, a relationship was proposed between the shear-flow barrier $W$ and the shear modulus $G$ for a frozen-in atomic configuration at the glass transition temperature $T_{g}$, given by $W\left(T_{g}\right) \propto G\left(T_{g}\right) v_{m}\left(T_{g}\right),{ }^{7}$ where $v_{m}$ is the molar volume, which usually varies little within an alloy family. Aside from their high $G$, the brittle behavior of these glasses can also be predicted by their high $T_{g}$, which for some compositions exceeds $600{ }^{\circ} \mathrm{C} .{ }^{1,2}$ The glass transition temperature is also a measure of $W\left(T_{g}\right)$, since the requirement for the liquid viscosity at $T_{g}\left(10^{12}\right.$ Pa s) gives $W\left(T_{g}\right) \approx 37 R T_{g}{ }^{7-9}$ Such

\footnotetext{
a) Author to whom correspondence should be addressed. Electronic mail: marios@caltech.edu.
}

high $G$ and $T_{g}$ therefore imply a high barrier for shear flow, which explains the high resistance of these glasses to relax stress by undergoing shear flow.

In this study, bulk glasses derived from the classic $\mathrm{Fe}_{80} \mathrm{P}_{12.5} \mathrm{C}_{7.5}$ glass-forming system are considered. This system was introduced by Duwez and $\operatorname{Lin}^{10}$ in 1967, who reported formation of glassy foils $50 \mu \mathrm{m}$ in thickness. Subsequent investigations revealed that glassy $\mathrm{Fe}-\mathrm{P}-\mathrm{C}$ microwires exhibit a rather high bending ductility. ${ }^{11}$ The ductility is associated with a relatively low $T_{g}$, reported to be $\sim 400{ }^{\circ} \mathrm{C},{ }^{10}$ and a relatively low $G$. Using the uniaxial yield strength of $\mathrm{Fe}-\mathrm{P}-\mathrm{C}$ of $\sim 3000 \mathrm{MPa}$ and the universal shear elastic limit for metallic glasses of $0.0267,{ }^{7}$ a shear modulus of $\sim 56 \mathrm{GPa}$ can be expected. Owing to such low $G$ and $T_{g}$, one would expect the $\mathrm{Fe}-\mathrm{P}-\mathrm{C}$ glass to also exhibit high toughness. The plane-stress fracture toughness of glassy $\mathrm{Fe}-\mathrm{P}-\mathrm{C}$ ribbons was measured to be $32 \mathrm{MPa} \mathrm{m}{ }^{1 / 2},{ }^{12}$ a value substantially higher than that of the bulk glasses in Refs. 1 and 2. In 1999, Shen and Schwarz ${ }^{13}$ reported development of bulk glassy alloys derived from the $\mathrm{Fe}-\mathrm{P}-\mathrm{C}$ system. Specifically, they demonstrated that alloys in the system $(\mathrm{Fe}, \mathrm{Co}, \mathrm{Cr}, \mathrm{Mo}, \mathrm{Ga})-\mathrm{P}-(\mathrm{C}, \mathrm{B})$ form glassy rods with diameters up to $4 \mathrm{~mm}$. More recently, the alloy systems of (Fe,Mo)-P-(C,B), ${ }^{5,14}$ (Fe,Mo)-(P,Si)-(C,B), ${ }^{15}$ $(\mathrm{Fe}, \mathrm{Cr}, \mathrm{Mo})-\mathrm{P}-(\mathrm{C}, \mathrm{B}){ }^{5} \quad(\mathrm{Fe}, \mathrm{Ni}, \mathrm{Mo})-\mathrm{P}-(\mathrm{C}, \mathrm{B}),{ }^{16}$ and (Fe,Co,Mo)-(P,Si)-(C,B) (Ref. 17) have been explored, all of which were found to form bulk glasses with critical rod diameters between 2 and $6 \mathrm{~mm}$. The glass-transition temperatures and shear moduli of these alloys, however, are not particularly low, with $T_{g}$ as high as $470{ }^{\circ} \mathrm{C}$ (Ref. 17) and $G$ of nearly $70 \mathrm{GPa}$ (Ref. 5) reported.

The aim of the present approach was to develop bulkglassy alloys with $T_{g}$ and $G$ not much higher than $\mathrm{Fe}_{80} \mathrm{P}_{12.5} \mathrm{C}_{7.5}$, such that a favorable glass-forming abilitytoughness relationship is attained. The compositions ${ }^{18}$ and critical rod diameters are listed in Table I. Thermal scans are presented in Fig. 1 and $T_{g}$ 's are listed in Table I. The elastic constants of the bulk glasses were evaluated using ultrasonic tests with $25-\mathrm{MHz}$ transducers along with density measurements. The results of the development strategy can be summarized as follows: substitution of $2.5 \% \mathrm{C}$ by $\mathrm{B}$ in $\mathrm{Fe}_{80} \mathrm{P}_{12.5} \mathrm{C}_{7.5}$ yielded glassy rods $0.5 \mathrm{~mm}$ in diameter; further substitution of $5.5 \% \mathrm{Fe}$ by $\mathrm{Mo}$ in $\mathrm{Fe}_{80} \mathrm{P}_{12.5}\left(\mathrm{C}_{5} \mathrm{~B}_{2.5}\right)$ yielded 3 
TABLE I. Glass-transition temperature $T_{g}$, critical rod diameter $d_{c}$, molar volume $v_{m}$, shear modulus $G$, bulk modulus $B$, and notch toughness $K_{Q}$ for $(\mathrm{Fe}, \mathrm{Cr}, \mathrm{Ni}, \mathrm{Mo})-\mathrm{P}-(\mathrm{C}, \mathrm{B})$ glassy alloys.

\begin{tabular}{|c|c|c|c|c|c|c|}
\hline Composition & $\begin{array}{c}T_{g} \\
\left({ }^{\circ} \mathrm{C}\right)\end{array}$ & $\begin{array}{c}d_{c} \\
(\mathrm{~mm})\end{array}$ & $\begin{array}{c}v_{m} \\
\left(\mathrm{~m}^{3} / \mathrm{mol}\right)\end{array}$ & $\begin{array}{c}G \\
(\mathrm{GPa})\end{array}$ & $\begin{array}{c}B \\
(\mathrm{GPa})\end{array}$ & $\begin{array}{c}K_{Q} \\
\left(\mathrm{MPa} \mathrm{m}^{1 / 2}\right)\end{array}$ \\
\hline $\mathrm{Fe}_{80} \mathrm{P}_{12.5} \mathrm{C}_{7.5}$ & 405 & $0.05^{\mathrm{a}}$ & $\cdots$ & $56^{\mathrm{b}}$ & $\cdots$ & $32^{\mathrm{c}}$ \\
\hline $\mathrm{Fe}_{80} \mathrm{P}_{12.5}\left(\mathrm{C}_{5} \mathrm{~B}_{2.5}\right)$ & 412 & 0.5 & $\cdots$ & $\cdots$ & $\cdots$ & $\cdots$ \\
\hline$\left(\mathrm{Fe}_{74.5} \mathrm{Mo}_{5.5}\right) \mathrm{P}_{12.5}\left(\mathrm{C}_{5} \mathrm{~B}_{2.5}\right)$ & 429 & 3 & $6.85 \times 10^{-6}$ & $56.94 \pm 0.09$ & $145.0 \pm 0.3$ & $53.1 \pm 2.4$ \\
\hline$\left(\mathrm{Fe}_{70} \mathrm{Mo}_{5} \mathrm{Ni}_{5}\right) \mathrm{P}_{12.5}\left(\mathrm{C}_{5} \mathrm{~B}_{2.5}\right)$ & 423 & 4 & $6.89 \times 10^{-6}$ & $57.31 \pm 0.08$ & $150.1 \pm 0.4$ & $49.8 \pm 4.2$ \\
\hline$\left(\mathrm{Fe}_{68} \mathrm{Mo}_{5} \mathrm{Ni}_{5} \mathrm{Cr}_{2}\right) \mathrm{P}_{12.5}\left(\mathrm{C}_{5} \mathrm{~B}_{2.5}\right)$ & 426 & 6 & $6.87 \times 10^{-6}$ & $57.94 \pm 0.07$ & $149.7 \pm 0.3$ & $44.2 \pm 4.6$ \\
\hline
\end{tabular}

${ }^{\mathrm{a}}$ Critical foil thickness attainable by splat quenching or melt spinning (Ref. 10).

${ }^{\mathrm{b}}$ Estimated using the uniaxial yield strength of $\sim 3000 \mathrm{MPa}$ and the universal shear elastic limit of 0.0267 (Ref. 7).

'Plane-stress fracture toughness value measured by Kimura and Masumoto using "trouser-leg" type shear tests (Ref. 12).

mm diameter glassy rods; substitution of $10 \%$ Fe by $5 \%$ Mo and $5 \% \mathrm{Ni}$ in $\mathrm{Fe}_{80} \mathrm{P}_{12.5}\left(\mathrm{C}_{5} \mathrm{~B}_{2.5}\right)$ yielded $4 \mathrm{~mm}$ diameter glassy rods; finally substitution of $12 \% \mathrm{Fe}$ by $5 \% \mathrm{Mo}, 5 \%$ $\mathrm{Ni}$, and $2 \% \mathrm{Cr}$ in $\mathrm{Fe}_{80} \mathrm{P}_{12.5}\left(\mathrm{C}_{5} \mathrm{~B}_{2.5}\right)$ yielded $6 \mathrm{~mm}$ diameter glassy rods. As shown in Table I, glass-forming ability improves dramatically while $T_{g}$ and $G$ increase only slightly on going from the parent $\mathrm{Fe}_{80} \mathrm{P}_{12.5} \mathrm{C}_{7.5}$ to the bulk-glass compositions.

For the notch toughness tests, $2 \mathrm{~mm}$ diameter glassy rods of $\left(\mathrm{Fe}_{74.5} \mathrm{Mo}_{5.5}\right) \mathrm{P}_{12.5}\left(\mathrm{C}_{5} \mathrm{~B}_{2.5}\right),\left(\mathrm{Fe}_{70} \mathrm{Mo}_{5} \mathrm{Ni}_{5}\right) \mathrm{P}_{12.5}\left(\mathrm{C}_{5} \mathrm{~B}_{2.5}\right)$, and $\left(\mathrm{Fe}_{68} \mathrm{Mo}_{5} \mathrm{Ni}_{5} \mathrm{Cr}_{2}\right) \mathrm{P}_{12.5}\left(\mathrm{C}_{5} \mathrm{~B}_{2.5}\right)$ were utilized. ${ }^{19}$ The stress intensity factor for the cylindrical configuration was evaluated using the analysis by Murakami. ${ }^{20}$ Considering that the average ligament size in the present specimens was $\sim 1 \mathrm{~mm}$, and taking the yield strength for this family of glasses to be $\sim 3200 \mathrm{MPa},{ }^{5,14,16,17}$ nominally plane strain conditions can be assumed for fracture toughness measurements of $<60 \mathrm{MPa} \mathrm{m}^{1 / 2}$, as obtained here. Nevertheless, since sharp precracks ahead of the notches were not introduced in the present specimens the measured stress intensity factors are not standard $K_{\mathrm{IC}}$ values. Thus, direct comparison of the notch toughness, $K_{Q}$, evaluated in this study with standard $K_{\mathrm{IC}}$ values for conventional metals is inappropriate. Nonetheless, $K_{Q}$ data provide useful information about the variation in the resistance to fracture within a set of uniformly tested materials. Due to inherent critical-castingthickness limitations, notch toughness measurements using cylindrical specimens with no pre-existing cracks are often reported for amorphous metals. ${ }^{21,22}$ More specifically, the

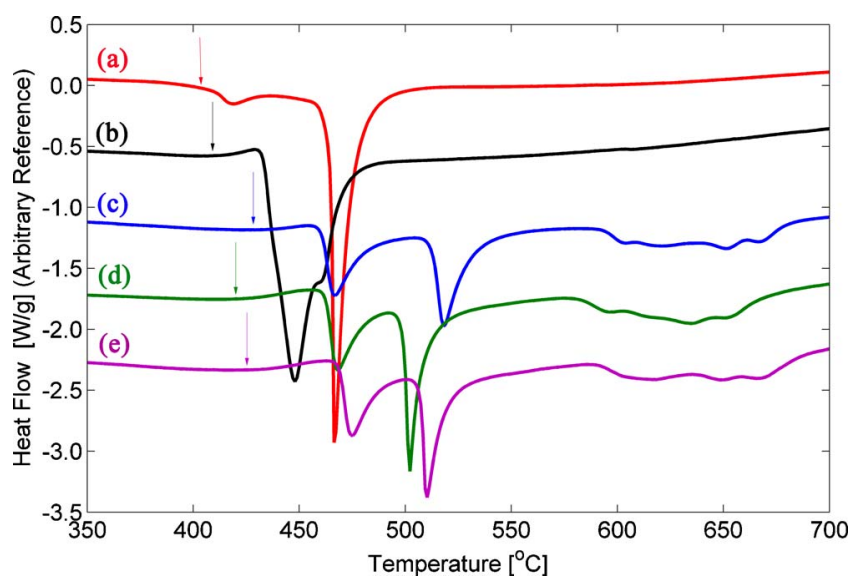

FIG. 1. (Color online) Differential scanning calorimetry at $20 \mathrm{~K} / \mathrm{min}$ scan rate for (a) $\mathrm{Fe}_{80} \mathrm{P}_{12.5} \mathrm{C}_{7.5}$ (b) $\mathrm{Fe}_{80} \mathrm{P}_{12.5}\left(\mathrm{C}_{5} \mathrm{~B}_{2.5}\right)$, (c) $\left(\mathrm{Fe}_{74.5} \mathrm{Mo}_{5.5}\right) \mathrm{P}_{12.5}\left(\mathrm{C}_{5} \mathrm{~B}_{2.5}\right)$, (d) $\left(\mathrm{Fe}_{70} \mathrm{Mo}_{5} \mathrm{Ni}_{5}\right) \mathrm{P}_{12.5}\left(\mathrm{C}_{5} \mathrm{~B}_{2.5}\right)$, and (e) $\left(\mathrm{Fe}_{68} \mathrm{Mo}_{5} \mathrm{Ni}_{5} \mathrm{Cr}_{2}\right) \mathrm{P}_{12.5}\left(\mathrm{C}_{5} \mathrm{~B}_{2.5}\right)$. Arrows designate the glass transition onsets. notch toughness measurements performed recently for $\mathrm{Fe}$ based glasses by Lewandowski and co-workers ${ }^{6,23}$ using specimens with configurations and dimensions similar to the present work are suitable for direct comparison.

The measured notch toughness $K_{Q}$, along with the quoted errors representing standard deviations in values, is presented in Table I. Despite the relatively large uncertainty (attributed to processing defects often exceeding the small plastic zone size of these glasses) ${ }^{23}$ the data reveal a monotonically decreasing trend in $K_{Q}$ in going from the least to the best glass former. In Fig. 2 we display this trend by plotting $K_{Q}$ against the critical rod diameter $d_{c}$ The plot reveals a roughly linear trend. On the same plot we present $K_{Q}$ versus $d_{c}$ for Fe-based glassy alloys developed by Poon and co-workers ${ }^{2,3,5,24}$ and tested by Lewandowski and co-workers. ${ }^{6,23}$ Although the data for those glasses are more scattered, linear regression reveals a toughness versus glassforming ability correlation of similar slope but lying well below the correlation shown by the present data.

According to arguments presented earlier, $K_{Q}$ can be expected to scale inversely with $W$. Since $W$ is understood to be linearly dependent on $G v_{m},{ }^{7}$ one can expect $K_{Q}$ to decrease with $G v_{m}$. In Fig. 3(a) we plot $K_{Q}$ against the product of the measured $G$ and $v_{m}$ for the present alloys. As shown in the plot, $K_{Q}$ decreases roughly linearly with $G v_{m}$. When $d_{c}$ is plotted against $G v_{m}$, however [Fig. 3(b)], a near-linear increasing trend is revealed which points to a scaling tendency between $d_{c}$ and $G v_{m}$, or more precisely, between $d_{c}$ and $W$. This scaling tendency suggests that glass-forming ability is

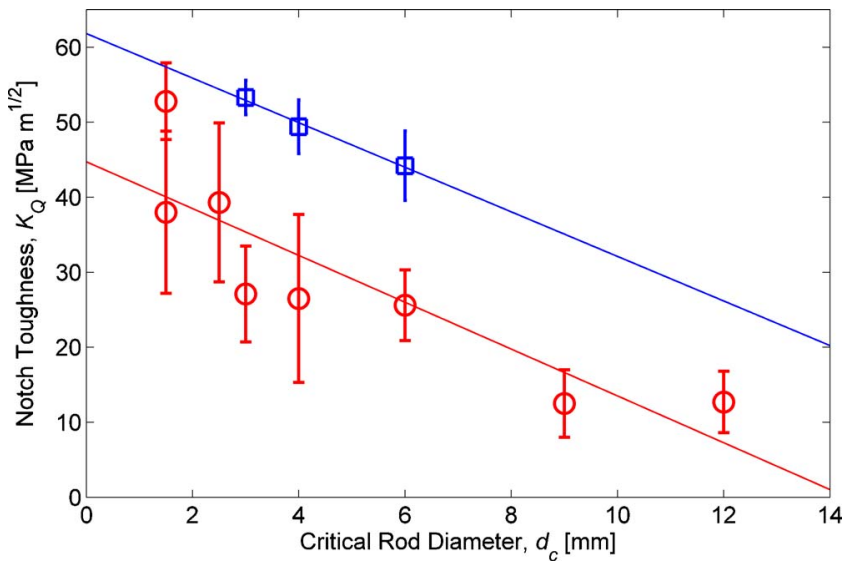

FIG. 2. (Color online) Notch toughness vs critical rod diameter for $\quad\left(\mathrm{Fe}_{74.5} \mathrm{Mo}_{5.5}\right) \mathrm{P}_{12.5}\left(\mathrm{C}_{5} \mathrm{~B}_{2.5}\right), \quad\left(\mathrm{Fe}_{70} \mathrm{Mo}_{5} \mathrm{Ni}_{5}\right) \mathrm{P}_{12.5}\left(\mathrm{C}_{5} \mathrm{~B}_{2.5}\right), \quad$ and $\left(\mathrm{Fe}_{68} \mathrm{Mo}_{5} \mathrm{Ni}_{5} \mathrm{Cr}_{2}\right) \mathrm{P}_{12.5}\left(\mathrm{C}_{5} \mathrm{~B}_{2.5}\right)(\square)$, and for the Fe-based glasses in Refs. 2, 3, 5, and 24 and tested in Refs. 6 and $23(\bigcirc)$. Lines are regressions to data. 


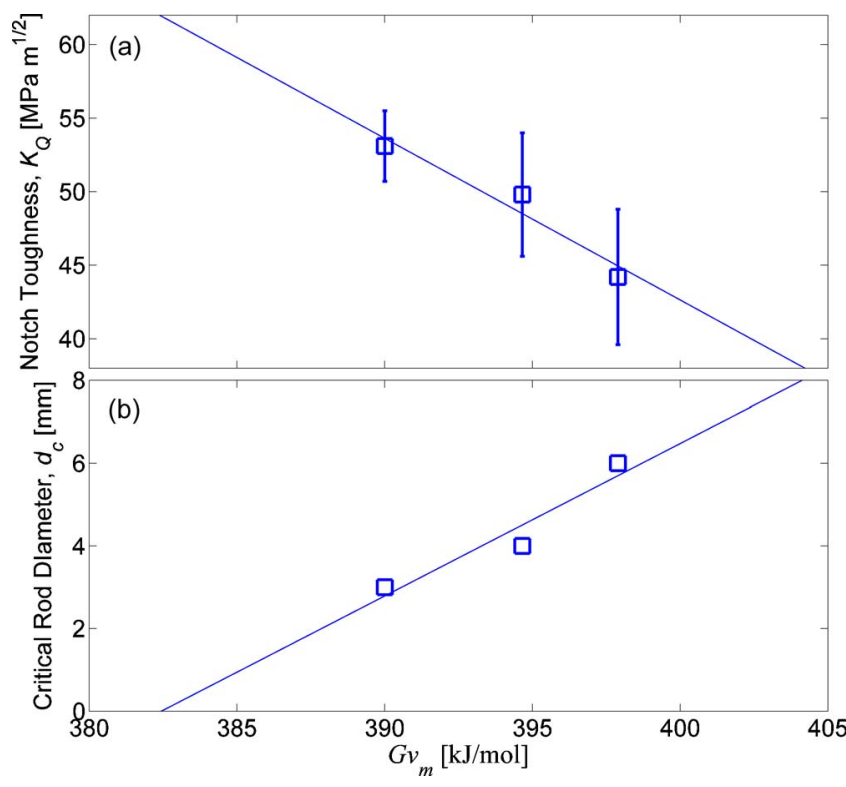

FIG. 3. (Color online) (a) Notch toughness vs $G v_{m}$ (b) and critical rod diameter vs $G v_{m}$ for $\left(\mathrm{Fe}_{74.5} \mathrm{Mo}_{5.5}\right) \mathrm{P}_{12.5}\left(\mathrm{C}_{5} \mathrm{~B}_{2.5}\right),\left(\mathrm{Fe}_{70} \mathrm{Mo}_{5} \mathrm{Ni}_{5}\right) \mathrm{P}_{12.5}\left(\mathrm{C}_{5} \mathrm{~B}_{2.5}\right)$, and $\left(\mathrm{Fe}_{68} \mathrm{Mo}_{5} \mathrm{Ni}_{5} \mathrm{Cr}_{2}\right) \mathrm{P}_{12.5}\left(\mathrm{C}_{5} \mathrm{~B}_{2.5}\right)(\square)$. Lines are regressions to data.

enhanced by increasing $W$. The interdependence of glassforming ability and toughness through $W$ explains the trend of monotonically and near-linearly decreasing $K_{Q}$ with increasing $d_{c}$ (Fig. 2). Furthermore, the relatively low $K_{Q}$ for a given $d_{c}$ demonstrated by the previously developed alloys suggests that their glass-forming ability arises from increasing $W$ to levels that considerably degrade toughness.

As discussed by Ponnambalam et al. ${ }^{25}$ the alloy development strategy that led to the bulk-glasses in Refs. 1 and 2 relied on attaining structurally rigid liquid configurations through heavy alloying. Structural reinforcement of the equilibrium liquid, they argue, is associated with the formation of a "backbone" liquid structure which gives rise to higher $T_{g}$ and higher isoconfigurational $G$. Ponnambalam et al..$^{25}$ therefore imply that such alloy development strategy relies on dramatically increasing $W$. In the present approach, bulkglass-forming compositions were derived directly from $\mathrm{Fe}_{80} \mathrm{P}_{12.5} \mathrm{C}_{7.5}$, a tough yet marginal glass former exhibiting a rather low $T_{g}$ and $G$. As shown in Table I, the present compositions are designed to improve glass-forming ability with respect to the parent $\mathrm{Fe}_{80} \mathrm{P}_{12.5} \mathrm{C}_{7.5}$ without raising $T_{g}$ and $G$. To put this argument into perspective, in Fig. 4 we plot $G v_{m}$ versus $R T_{g}$ data $^{26}$ for the present and previously developed Fe-based glasses. The combined data reveal a one-to-one correspondence between $G v_{m}$ and $R T_{g}$ that extends over a broad range. Such correspondence is expected, since both $G v_{m}$ and $R T_{g}$ are independent measures of $W$. Interestingly though, the data for the present glasses lie at the low-end of the correlation, supporting that the configurations formed by the present glasses are indeed associated with lower $W$.

This work was supported in part by the MRSEC Program of the National Science Foundation under Award Number DMR-0520565. Useful discussions with M.E. Launey and M.L. Lind are gratefully acknowledged.

${ }^{1}$ Z. P. Lu, C. T. Liu, J. R. Thompson, and W. D. Porter, Phys. Rev. Lett. 92, 245503 (2004)

${ }^{2}$ V. Ponnambalam, S. J. Poon, and G. J. Shiflet, J. Mater. Res. 19, 1320 (2004).

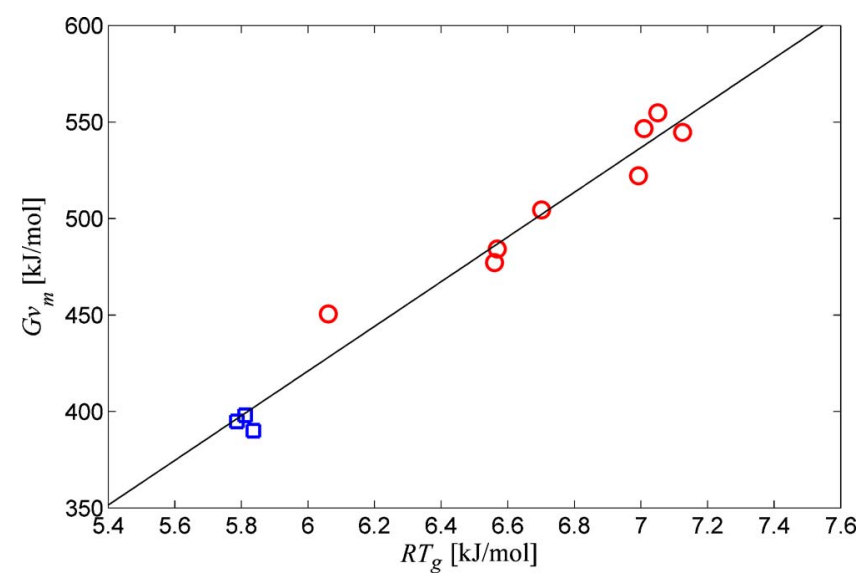

FIG. 4. (Color online) $G v_{m}$ vs $R T_{g}$ for $\left(\mathrm{Fe}_{74.5} \mathrm{Mo}_{5.5}\right) \mathrm{P}_{12.5}\left(\mathrm{C}_{5} \mathrm{~B}_{2.5}\right)$, $\left(\mathrm{Fe}_{70} \mathrm{Mo}_{5} \mathrm{Ni}_{5}\right) \mathrm{P}_{12.5}\left(\mathrm{C}_{5} \mathrm{~B}_{2.5}\right)$, and $\left(\mathrm{Fe}_{68} \mathrm{Mo}_{5} \mathrm{Ni}_{5} \mathrm{Cr}_{2}\right) \mathrm{P}_{12.5}\left(\mathrm{C}_{5} \mathrm{~B}_{2.5}\right)$ ( $\left.\square\right)$, and for the Fe-based glasses in Refs. 2, 3, 5, and 24 tested in Refs. 6 and $23(\bigcirc)$. The line is a regression to all data.

${ }^{3}$ X. J. Gu, S. J. Poon, and G. J. Shiflet, J. Mater. Res. 22, 344 (2007).

${ }^{4}$ P. A. Hess, S. J. Poon, G. J. Shiflet, and R. H. Dauskardt, J. Mater. Res. 20, 783 (2005).

${ }^{5}$ X. J. Gu, S. J. Poon, G. J. Shiflet, and M. Widom, Acta Mater. 56, 88 (2008).

${ }^{6}$ J. J. Lewandowski, X. J. Gu, A. S. Nouri, S. J. Poon, and G. J. Shiflet, Appl. Phys. Lett. 92, 091918 (2008).

${ }^{7}$ W. L. Johnson and K. Samwer, Phys. Rev. Lett. 95, 195501 (2005).

${ }^{8}$ M. D. Demetriou, J. S. Harmon, M. Tao, G. Duan, K. Samwer, and W. L. Johnson, Phys. Rev. Lett. 97, 065502 (2006).

${ }^{9}$ W. L. Johnson, M. D. Demetriou, J. S. Harmon, M. L. Lind, and K. Samwer, MRS Bull. 32, 644 (2007).

${ }^{10}$ P. Duwez and S. C. H. Lin, J. Appl. Phys. 38, 4096 (1967).

${ }^{11}$ A. Inoue, M. Hagiwara, and T. Masumoto, J. Mater. Sci. 17, 580 (1982).

${ }^{12}$ H. Kimura and T. Masumoto, Scr. Metall. 9, 211 (1975).

${ }^{13}$ T. D. Shen and R. B. Schwarz, Appl. Phys. Lett. 75, 49 (1999)

${ }^{14}$ T. Zhang, F. Liu, S. Pang, and R. Li, Mater. Trans. 48, 1157 (2007).

${ }^{15}$ B. Shen, M. Akiba, and A. Inoue, Appl. Phys. Lett. 88, 131907 (2006).

${ }^{16}$ F. Liu, Q. Yang, S. Pang, C. Ma, and T. Zhang, Mater. Trans. 49, 231 (2008).

${ }^{17}$ F. Li, B. Shen, A. Makino, and A. Inoue, Appl. Phys. Lett. 91, 234101 (2007).

${ }^{18}$ Alloy ingots were prepared by induction melting mixtures of the appropriate amounts of $\mathrm{Fe}(99.95 \%)$, Mo (99.95\%), Ni (99.995\%), Cr (99.99\%), B crystal (99.5\%), graphite powder (99.9995\%), and P (99.9999\%) in quartz tubes sealed under argon atmosphere. A 50- $\mu$ m-thick $\mathrm{Fe}_{80} \mathrm{P}_{12.5} \mathrm{C}_{7.5}$ foil was prepared using an Edmund Buhler D-7400 splat quencher. All other alloys were formed into cylindrical rods by remelting the ingots in quartz tubes of 0.5 -mm-thick walls under argon atmosphere and rapidly water quenching. X-ray diffraction with $\mathrm{Cu} K \alpha$ radiation was performed to verify the amorphous nature of the foils and rods.

${ }^{19}$ The specimen rods were notched using a wire saw with a root radius of $90 \mu \mathrm{m}$ to a depth of approximately half the rod diameter. The notched specimens were placed on a 3-pt bending fixture with span distance of $12.7 \mathrm{~mm}$. The critical fracture load was measured by applying a monotonically increasing load at constant cross-head speed of $0.1 \mathrm{~mm} / \mathrm{min}$. At least three tests were performed for each alloy.

${ }^{20}$ Y. Murakami, Stress Intensity Factors Handbook (Pergamon, Oxford, United Kingdom, 1987), Vol. 2, p. 666.

${ }^{21}$ P. Wesseling, T. G. Nieh, W. H. Wang, and J. J. Lewandowski, Scr. Mater. 51, 151 (2004).

${ }^{22}$ X. K. Xi, D. Q. Zhao, M. X. Pan, W. H. Wang, Y. Wu, and J. J. Lewandowski, Phys. Rev. Lett. 94, 125510 (2005).

${ }^{23}$ A. Shamimi Nouri, X. J. Gu, S. J. Poon, G. J. Shiflet, and J. J. Lewandowski, Philos. Mag. Lett. 88, 853 (2008).

${ }^{24}$ X. J. Gu, S. J. Poon, and G. J. Shiflet, Scr. Mater. 57, 289 (2007).

${ }^{25}$ V. Ponnambalam, S. J. Poon, G. J. Shiflet, V. M. Keppens, R. Taylor, and G. Petculescu, Appl. Phys. Lett. 83, 1131 (2003).

${ }^{26}$ The molar volumes of the alloys developed by Poon and co-workers (Refs. $2,3,5$, and 24) were estimated using $v_{m}=\sum_{i} x_{i} M_{i} / \rho_{i}$, where $x_{i}, M_{i}$, and $\rho_{i}$ are the atomic fraction, atomic weight, and density of element $i$, respectively. For elements $\mathrm{P}, \mathrm{C}$, and $\mathrm{B}, \rho_{i}$ is estimated using the metallic radius. 